\title{
The increase of adenylate kinase activity in the blood can control aggregation of platelets in coronary or peripheral arterial ischemia
}

\author{
Bożena Studzińska, Anna Seroka, Marta Łępicka, Katarzyna Roszek, Michał Komoszyński \\ Biochemistry Department, Institute of General and Molecular Biology, Nicolaus Copernicus University, Toruń, Poland; \\ michkom@chem.uni.torun.pl
}

Received 15 November 2009; revised 21 December 2009; accepted 24 December 2009.

\section{ABSTRACT}

Activation and aggregation of blood platelets is crucial for hemostasis and thrombosis. In the vascular system adenine nucleotides are important signaling molecules playing a key role in hemostasis. ADP was the first low molecular weight agent recognized to cause blood platelets activation and aggregation. NTPDases and adenylate kinase (AK) are the main enzymes involved in metabolism of extracellular adenine nucleotides. The majority of studies concentrated on the role of NTPDase1 (apyrase) in the inhibition of platelets aggregation. Up to now, there are still insufficient data concerning the role of $A K$ in this process. We found that adenylate kinase activity in the serum of patients with myocardial infarction is significantly increased when compared to the healthy volunteers. The elevated activity of AK is connected to appearance of another isoform of that enzyme, expressed in patients with myocardial infarction. The influence of AK on the pig blood platelets aggregation induced by $20 \mu \mathrm{M}$ ADP or $7.5 \mu \mathrm{g} / \mathrm{ml}$ rat collagen was examined. $1 U$ of adenylate kinase added to platelet-rich plasma (PRP) before ADP or collagen, inhibited the platelets aggregation. One minute after induction of platelets activation by ADP as much as $5 U$ of adenylate kinase was necessary to stop the platelet aggregation. In the case of collagen activated aggregation, only $2 U$ of $A K$ added 1 or 5 minutes after initiation of the aggregation process were sufficient for disaggregation of platelets. The increase of ATP: ADP ratio is probably responsible for the initiation of disaggregation process. We conclude that adenylate kinase is involved in regulation of platelets aggregation. Anticoagulative role of AK indicates the possibility of using this enzyme in the treatment of cardiovascular diseases.

Keywords: Hemostasis; Platelets Aggregation; Adenylate Kinase

\section{INTRODUCTION}

It is well known that platelets aggregation is the key process in thrombosis. Platelets hyperaggregability is associated with the risk factors for cerebral, coronary or peripheral arterial ischemia causing stroke, cardiovascular disease and venous thrombosis [1,2]. The WHO estimated that 12.6 percent of deaths worldwide are caused by the ischemic heart disease, that is the leading cause of death in the developed countries [3]. The novel therapies against platelet-dependent thrombosis are targeted at purinergic receptor (P2Y12) activating the platelets aggregation. In the last few years the thienopyridyne derivatives (ticlopidine, clopidogrel, prasugrel) are mainly used.

Adenine nucleotides play an important role in blood platelets function. Platelets possess three purinergic receptors for ecto-nucleotides: P2Y1 and P2Y12, which interact with ADP, and P2X1, which interacts with ATP [4-6]. The interaction of adenine nucleotides with their receptors activates platelets and leads to their aggregation. Among the nucleotides, ADP is a key molecule involved in hemostasis and development of arterial thrombosis [7-9]. Furthermore, ATP stimulation of P2X1 triggers off the platelets shape change and helps to amplify platelet responses mediated by agonists such as collagen. Activation of each of these nucleotide receptors results in unique signal transduction pathways that are important in the regulation of hemostasis and thrombosis [10].

The most important enzymes metabolizing ectoncleotides in the vascular system are: NTPDase1 (EC 3.6.1.5), NTPDase2 (EC 3.6.1.5), 5'-nucleotidase (EC 2.7.4.6), adenosine deaminase (EC 3.5.4.4) and adenylate kinase (EC 2.7.4.3) [8-10]. These enzymes maintain the 
proper level of purine nucleotides.

NTPDase1 (apyrase, CD39) metabolizes ATP and ADP to AMP. Its role in blocking the platelet aggregation triggered by ADP is well recognized $[14,15]$. The decreased activity of NTPDase1 in the atherosclerotic arteries proves its important regulatory function in thrombosis [13].

Adenylate kinase (AK) also participates in controlling the adenine nucleotides concentration due to transferring the phosphate group between ATP, ADP and AMP [1719]. Some authors suggest, that serum adenylate kinase is responsible for the clearance of circulating ADP and therefore blocks activation of platelets $[11,20]$. Based on these information, adenylate kinase may be useful in the regulation of platelets activity. The research results published in the 1970s show the increased AK activity in serum and urine of patients in the early phase of myocardial infarction [21,22]. However, there are still insufficient data concerning the adenylate kinase influence on the platelets aggregation [23].

The aim of our research was to determine the role of adenylate kinase in the regulation of platelets aggregation.

\section{MATERIALS AND METHODS}

Reagents. The following reagents were used: ethanolamine, n-heptane, $\mathrm{KCl}, \mathrm{HClO}_{4}$ and EDTA (POCh Gliwice, Poland, p.a. grade), $\mathrm{KH}_{2} \mathrm{PO}_{4}, \mathrm{~K}_{2} \mathrm{HPO}_{4}$, tetrabutylammonium hydrogen sulphate (TBA) and isocratic methanol (Baker Phillipsburg, USA, HPLC grade). Adenylate kinase (AK) from Bacillus stearothermophilus, potato NTP-Dase1 (apyrase), ADP, rat collagen and other reagents were purchased from Sigma Chemical Co. (USA).

Materials. Human serum was obtained from blood samples taken from healthy volunteers and patients with myocardial infarction collected not later than 3 hours after the incident in the WSZ Hospital, Torun (Poland).

Platelet-rich plasma (PRP) was prepared from fresh pig blood samples. The whole citrated blood was centrifuged at $200 \times \mathrm{g}$ for $20 \mathrm{~min}$ in temperature $10^{\circ} \mathrm{C}$ and the resulted supernatant was used in the experiments.

Platelet aggregation. All the experiments were conducted in $37^{\circ} \mathrm{C}$. To $800 \mu \mathrm{l}$ sample of PRP (containing $246 \times 10^{3}$ to $458 \times 10^{3}$ platelets in $\mu$ l counted by Sysmex K-1000 hematology analyzer) the appropriate am- ounts of ADP, rat collagen and adenylate kinase was added. The platelet aggregation was monitored by spectrophotometric measurement at $\lambda=600 \mathrm{~nm}$.

The appropriate amount of the adenylate kinase was added to the PRP together with ADP or collagen, 1 minute or 5 minutes after initiation of the aggregation, respectively.

Assay of nucleotides. The qualitative and quantitative analysis of purines in the reaction mixtures was made by the HPLC method [21]. The samples were separated on the Nova-Pack $\mathrm{C}_{18}$ column, $3.9 \mathrm{~mm} \times 150 \mathrm{~mm}$ (Waters Co., Milford, MA, USA). The presence of purines was detected at $\lambda=260 \mathrm{~nm}$.

Adenylate kinase activity determination. $50 \mu \mathrm{l}$ diluted human serum was added to $50 \mu \mathrm{l}$ reaction mixture $(2 \mathrm{mM}$ ADP, $1.5 \mathrm{mM} \mathrm{MgCl}_{2}$ and $0.1 \mathrm{mM}$ suramin in $50 \mathrm{mM}$ Hepes, $\mathrm{pH}$ 7.6). The enzymatic reaction was terminated with $100 \mu \mathrm{l} 1 \mathrm{M} \mathrm{HClO}_{4}$. Then the samples were neutralized with $\mathrm{KOH}$ and delipidated with n-heptane. $20 \mu \mathrm{l}$ aliquots were analysed by the HPLC method [21].

Partial purification of adenylate kinase. Human serum from healthy volunteers and patients with myocardial infarction was precipitated with ammonium sulfate (35\% saturation and the obtained supernatant up to $85 \%$ saturation). The partially purified enzyme with the activity of $2.27 \mathrm{U}$ (healthy volunteers serum) or $17.3 \mathrm{U}$ (serum after myocardial infarction) was used in further experiments.

Affinity chromatography on Blue-Sepharose. The Blue -Sepharose column $(\varnothing 1.5 \mathrm{~cm} \times 13 \mathrm{~cm})$ was equilibrated with $10 \mathrm{mM}$ Tris-HCl buffer $\mathrm{pH} 7.4$ containing $1 \mathrm{mM}$ dithiotreitol and $0.1 \mathrm{mM}$ EDTA. Approximately $15 \mathrm{mg}$ of partially purified protein from the previous step was applied to the column. The proteins were eluted with the linear gradient of $0 \div 2 \mathrm{M} \mathrm{NaCl}$. One-milliliter fractions were collected and used to the determination of AK activity and protein concentration.

Statistical analysis. All data presented in this paper derive from 3 to 6 independent experiments. The results are expressed as mean $\pm \mathrm{SD}$.

\section{RESULTS}

Our experiments on the purine nucleotides metabolism in the human serum confirmed that adenylate kinase activity in patients with myocardial infarction is significantly increased when compared to the healthy volunteers (Figure 1).

The elution profile after Blue-Sepharose chromatography of partially purified human serum obtained from healthy volunteers and patients with myocardial infarction is also different (Figure 2). There were no significant changes in the NTPDase activity (data not shown). These data suggest that the elevated activity of AK is connected to appearance of another isoform of that enzyme, expressed only in patients with myocardial infarction.

To precisely explain the role of adenylate kinase in blood, the AK influence on the platelets aggregation process was determined. Simultaneously with the platelets aggregation we analyzed: a/ the concentration of purines and $b$ / the adenylate kinase influence of this process. These experiments provoked that a minimal vo- 
lume of PRP analyzed was $800 \mu \mathrm{l}$. Therefore, the measurement of platelet aggregation required using the spectrophotometer. The degree of platelet aggregation in pig blood is dependent on the ADP and rat collagen concentrations (Figure 3). Based on the experiments, we found that $20 \mu \mathrm{M}$ ADP and $7.5 \mu \mathrm{g} / \mathrm{ml}$ rat collagen were used in further experiments as sufficient to the efficient aggregation of pig blood platelets.

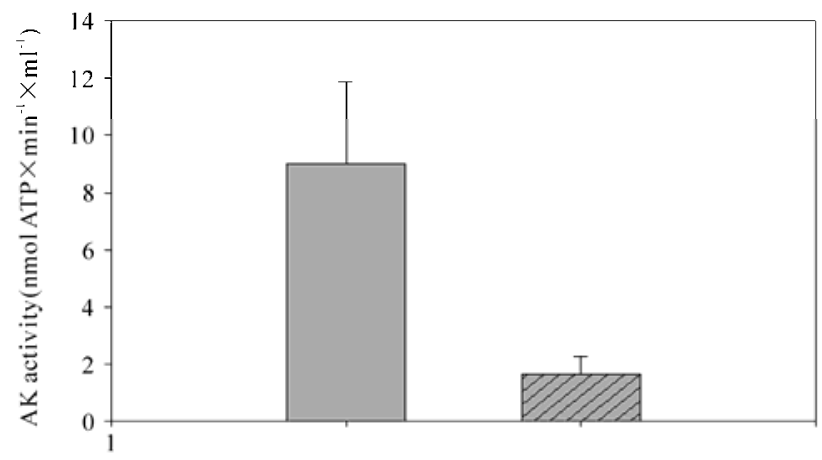

Figure 1. Comparison of the adenylate kinase activity in human serum of patients with myocardial infarction $(\square)$ and healthy volunteers (ש্]).

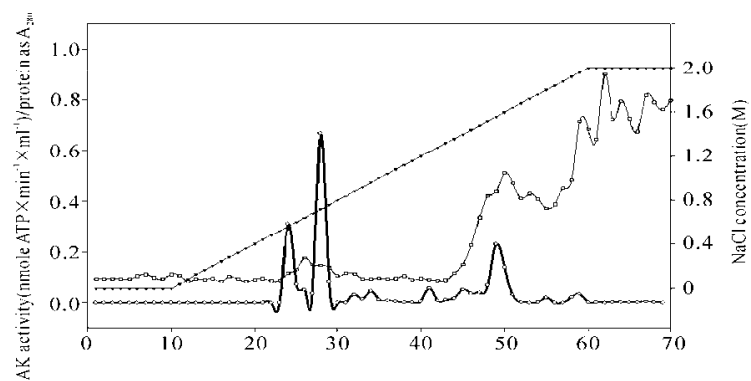

(a)

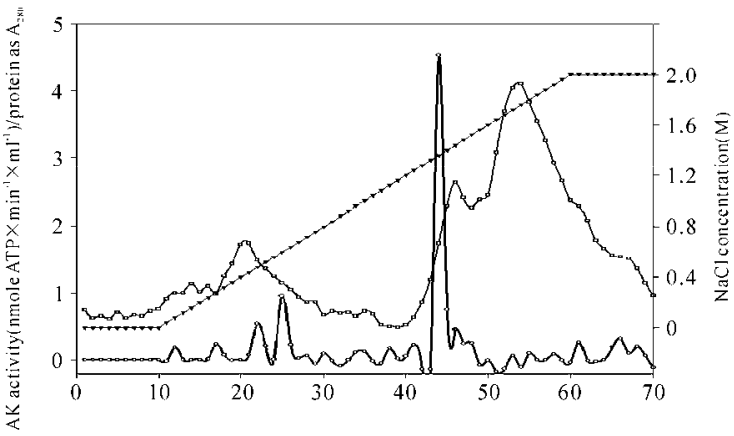

(b)

Figure 2. Elution profile after Blue-Sepharose chromatography of human serum preparation from healthy volunteers (a) and patients with myocardial infarction (b). Adenylate kinase activity of eluted fractions (-0-) was estimated with $2 \mathrm{mM}$ ADP as substrate. The protein concentration (- - ) was measured spectrophotometrically at $\lambda=280 \mathrm{~nm}$. $\mathrm{NaCl}$ concentration $(-\boldsymbol{\Delta}-)$ ranged from 0 to $2 \mathrm{M}$.

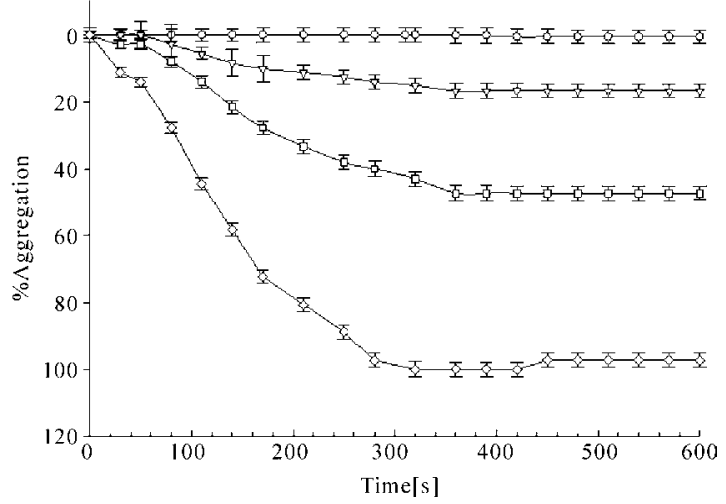

(a)

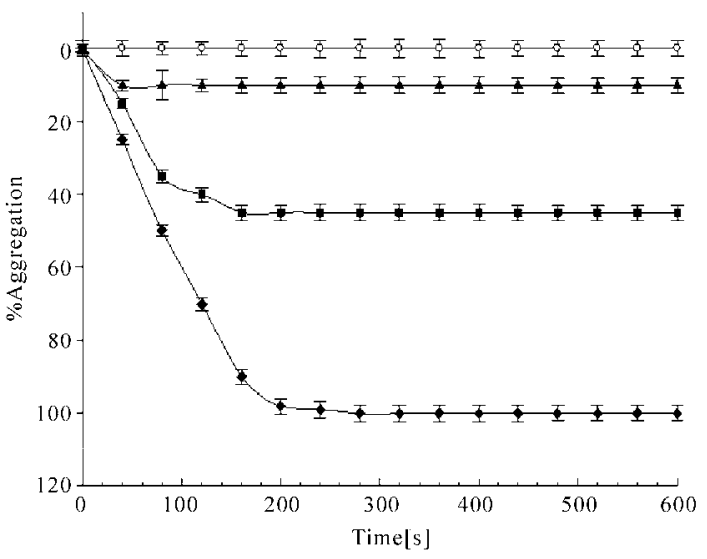

(b)

Figure 3. The influence of different concentrations of ADP (a) and rat collagen (b) on the platelets aggregation in PRP. Control PRP (-0-), PRP + $10 \mu \mathrm{M}$ ADP (- - -), PRP + $20 \mu \mathrm{M}$ ADP (一 —), PRP + $30 \mu \mathrm{M}$ ADP (— -),PRP $+5 \mu \mathrm{g} / \mathrm{ml}$ collagen $(-\boldsymbol{\Delta}-)$, PRP $+7.5 \mu \mathrm{g} / \mathrm{ml}$ collagen (一-), PRP $+10 \mu \mathrm{g} / \mathrm{ml}$ collagen $(-\bullet-)$.

The purines concentration was controlled after 10 minutes of incubation in $37^{\circ} \mathrm{C}$ in control PRP and in PRP activated by $20 \mu \mathrm{M}$ ADP or $7.5 \mu \mathrm{g} / \mathrm{ml}$ rat collagen (Table 1). Concentration of nucleotides and nucleosides differs between PRP activated by $20 \mu \mathrm{M}$ ADP and by $7.5 \mu \mathrm{g} / \mathrm{ml}$ rat collagen.

Table 1. Concentration of purines after 10 min incubation of control PRP, PRP activated by $20 \mu \mathrm{M}$ ADP and PRP activated by $7.5 \mu \mathrm{g} / \mathrm{ml}$ rat collagen.

\begin{tabular}{|c|c|c|c|c|}
\hline & \multicolumn{4}{|c|}{ Purines concentration $[\mu \mathrm{M}]$} \\
\hline & Ado & AMP & ADP & ATP \\
\hline Control PRP & $292.9 \pm 27.8$ & 0 & 0 & 0 \\
\hline $\begin{array}{c}\mathrm{PRP}+20 \mu \mathrm{M} \\
\mathrm{ADP}\end{array}$ & $1042.0 \pm 100.4$ & $46.0 \pm 6.7$ & $18.5 \pm 3.3$ & $14.3 \pm 2.4$ \\
\hline $\begin{array}{l}\mathrm{PRP}+7,5 \mu \mathrm{g} / \mathrm{m} \\
\text { l rat collagen }\end{array}$ & $2084.9 \pm 140.6$ & $66.7 \pm 6.3$ & $10.9 \pm 4.7$ & $26.3 \pm 11.3$ \\
\hline
\end{tabular}


Then the adenylate kinase influence on the aggregation process induced with the addition of $20 \mu \mathrm{M}$ ADP was analysed. The appropriate amount of the enzyme was added to the PRP together with ADP, 1 minute or 5 minutes after initiation of the aggregation, respectivelyFigures 4-7.

The presented results show that addition of $1 \mathrm{U}$ adenylate kinase before initiation of the aggregation processs by ADP effectively blocks aggregation (Figure 4). Addition of $5 \mathrm{U}$ adenylate kinase in 1 minute after platelets activation (Figure 6) or $6 \mathrm{U}$ in 5 minutes after activation (Figure 7), respectively, is necessary to stop the aggregation process. The purines concentration in the control PRP, in PRP after activating platelets with $20 \mu \mathrm{M}$ $\mathrm{ADP}$ and in the presence of adenylate kinase are summarized in Table 2.

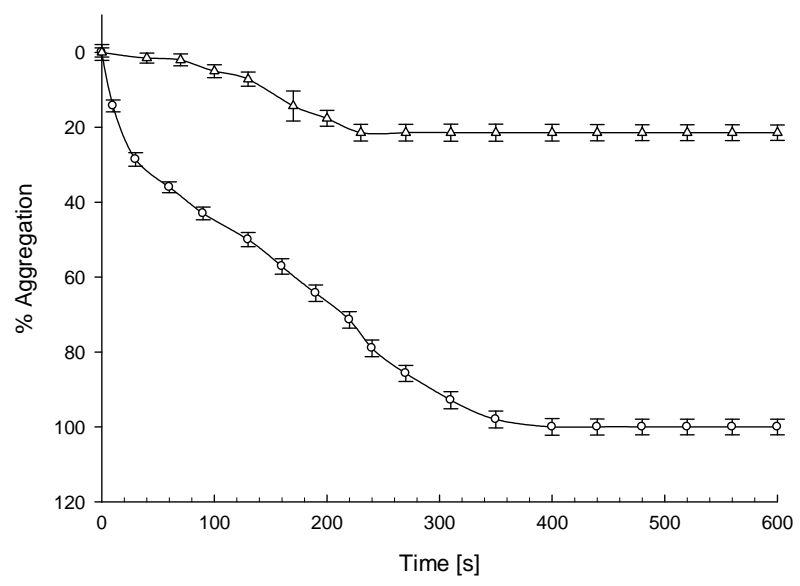

Figure 4. Influence of $1 U$ adenylate kinase (AK) on the platelets aggregation in PRP induced by $20 \mu \mathrm{M}$ ADP. Control PRP + $20 \mu \mathrm{M}$ ADP (—o-), PRP + $1 \mathrm{U}$ AK $+20 \mu \mathrm{M}$ ADP (- - -).

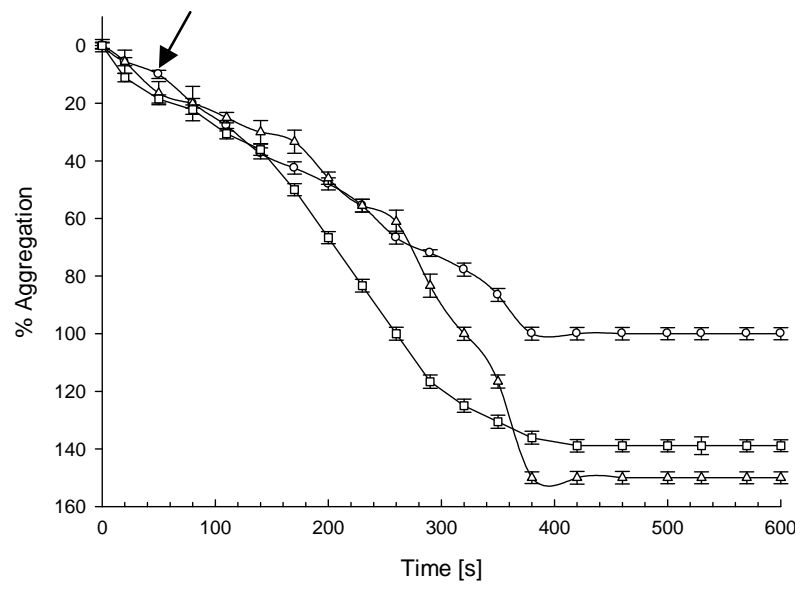

Figure 5. Influence of $1 \mathrm{U}$ and $2 \mathrm{U}$ adenylate kinase (AK) added 1 min after initiation of the platelets aggregation in PRP by 20 $\mu \mathrm{M}$ ADP. Control PRP $+20 \mu \mathrm{M}$ ADP $(-0-)$, PRP $+20 \mu \mathrm{M}$ $\mathrm{ADP}+1 \mathrm{U}$ AK after $1 \mathrm{~min} .(-\Delta-), \mathrm{PRP}+20 \mu \mathrm{M}$ ADP $+2 \mathrm{U}$ AK after 1 min. (- - ).

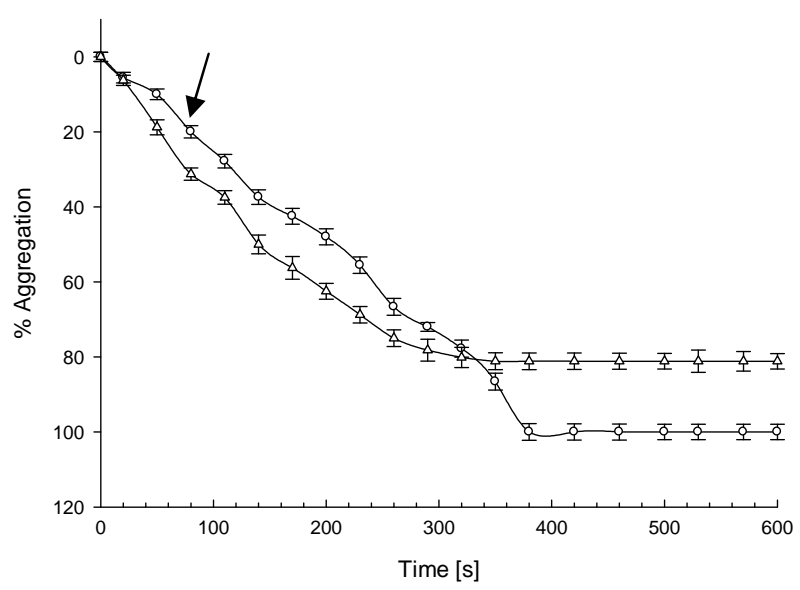

Figure 6. The influence of $5 \mathrm{U}$ adenylate kinase (AK) added 1 min after initiation of the platelets aggregation in PRP by $20 \mu \mathrm{M}$ ADP. Control PRP + $20 \mu \mathrm{M}$ ADP (-0-), PRP + $20 \mu \mathrm{M}$ ADP + $5 \mathrm{U}$ AK after 1 min. ( $-\Delta-)$.

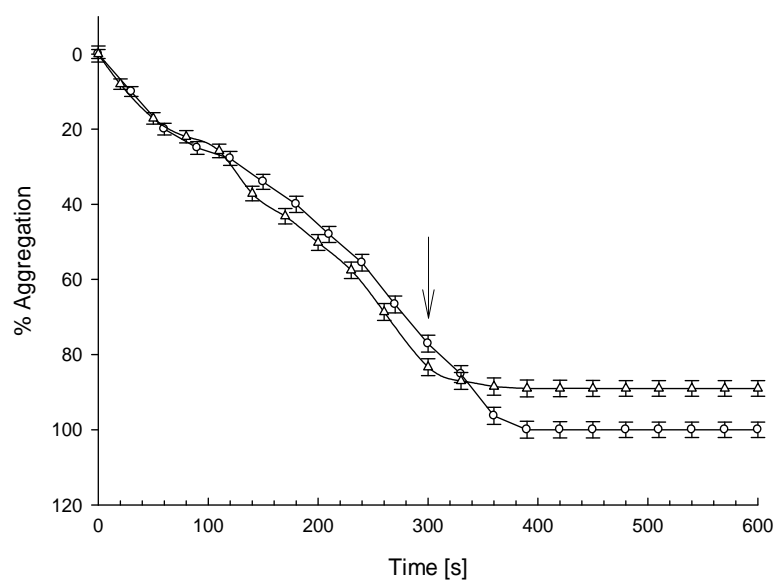

Figure 7. The influence of $6 \mathrm{U}$ adenylate kinase (AK) added 5 min after initiation of the platelets aggregation in PRP by $20 \mu \mathrm{M}$ ADP. Control PRP + $20 \mu \mathrm{M}$ ADP (-0-), PRP + $20 \mu \mathrm{M}$ ADP + $6 \mathrm{U}$ AK after 5 min. (- - -).

Table 2. Influence of AK on the concentration of purine nucleotides in PRP activated by $20 \mu \mathrm{M}$ ADP.

\begin{tabular}{|c|c|c|c|c|}
\hline \multirow{2}{*}{$\begin{array}{c}\text { Amount of } \\
\text { AK }\end{array}$} & \multirow{2}{*}{$\begin{array}{l}\text { Time of } \\
\text { enzyme } \\
\text { addition }\end{array}$} & \multicolumn{3}{|c|}{ Nucleotides concentration $[\mu \mathrm{M}]$} \\
\hline & & AMP & ADP & ATP \\
\hline No enzyme & - & $46.0 \pm 6.7$ & $18.5 \pm 3.3$ & $14.3 \pm 2.4$ \\
\hline $1 \mathrm{U}$ & $\begin{array}{l}\text { Before activa- } \\
\text { tion by ADP }\end{array}$ & $92.9 \pm 11.3$ & $21.5 \pm 4.6$ & $55.2 \pm 3.3$ \\
\hline $1 \mathrm{U}$ & $\begin{array}{l}1 \text { min after } \\
\text { activation by } \\
\text { ADP }\end{array}$ & $40.4 \pm 3.3$ & $52.3 \pm 5.8$ & $45.0 \pm 1.5$ \\
\hline $2 U$ & $\begin{array}{l}1 \text { min after } \\
\text { activation by } \\
\text { ADP }\end{array}$ & $49.3 \pm 0.7$ & $63.2 \pm 2.6$ & $67.9 \pm 1.9$ \\
\hline $5 U$ & $\begin{array}{l}1 \text { min after } \\
\text { activation by } \\
\text { ADP }\end{array}$ & $100.8 \pm 2.1$ & $23.6 \pm 4.5$ & $50.2 \pm 2.1$ \\
\hline $6 \mathrm{U}$ & $\begin{array}{l}5 \text { min after } \\
\text { activation by } \\
\text { ADP }\end{array}$ & $81.2 \pm 13.9$ & $22.9 \pm 1.3$ & $56.7 \pm 2.0$ \\
\hline
\end{tabular}


Inhibition of adenylate kinase activity by $20 \mu \mathrm{M}$ diadenosine pentaphosphate (AP5A) in the presence of ADP causes the platelets aggregation as in the control with ADP only (Figure 8). It proves that the aggregation process is inhibited in fact due to the adenylate kinase activity.

The adenylate kinase influence on the aggregation process induced by the addition of $7.5 \mu \mathrm{g} / \mathrm{ml}$ rat collagen was also analyzed. The appropriate amount of the enzyme was added to the PRP simultaneously with collagen, 1 minute or 5 minutes after initiation of the aggregation respectively (Figures 9-11).

The presented results show that only $2 \mathrm{U}$ of adenylate kinase added to PRP within 1 or 5 minute after initiation of the aggregation process cause an almost complete disaggregation of platelets. The purines concentration in control PRP, in PRP after activating the platelets with 7.5 $\mu \mathrm{g} / \mathrm{ml}$ rat collagen and in the presence of adenylate kinase are summarized in Table 3.

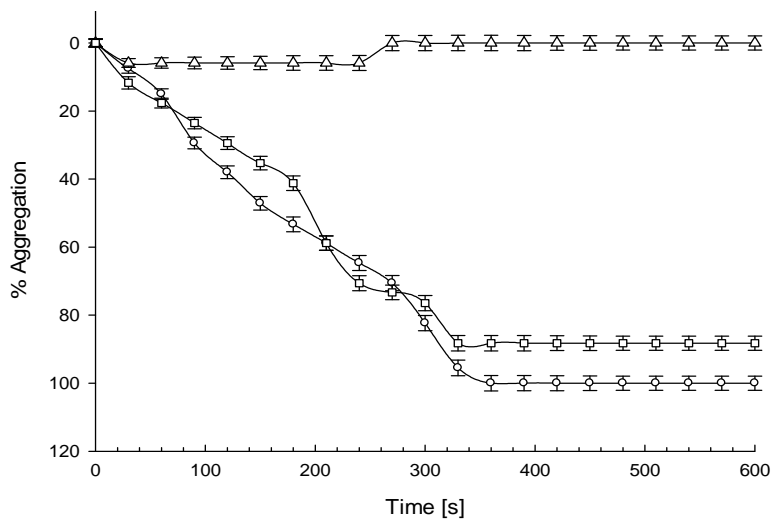

Figure 8. The influence of $20 \mu \mathrm{M}$ AP5A on the platelets aggregation in PRP in the presence of $1 \mathrm{U}$ adenylate kinase (AK). Control PRP + $20 \mu \mathrm{M}$ ADP (-0-), PRP + 1U AK + $20 \mu \mathrm{M}$ ADP $(-\Delta-)$, PRP $+20 \mu \mathrm{M}$ AP5A $+1 \mathrm{U}$ AK $+20 \mu \mathrm{M}$ ADP $(-\square-)$.

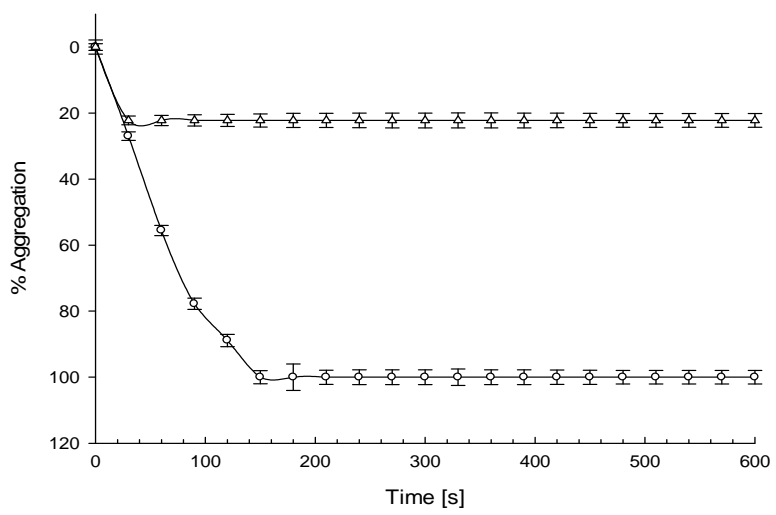

Figure 9. The influence of $1 \mathrm{U}$ adenylate kinase (AK) on the platelets aggregation in PRP induced by $7.5 \mu \mathrm{g} / \mathrm{ml}$ rat collagen. Control PRP + $7.5 \mu \mathrm{g} / \mathrm{ml}$ collagen (-0-), PRP + $1 \mathrm{U}$ AK + 7.5 $\mu \mathrm{g} / \mathrm{ml}$ collagen $(-\Delta-)$.

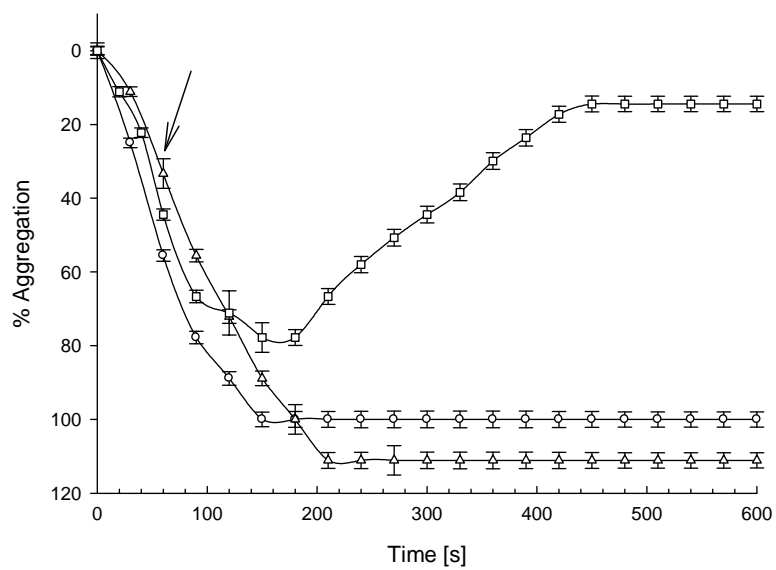

Figure 10. The influence of $1 \mathrm{U}$ and $2 \mathrm{U}$ adenylate kinase (AK) added $1 \mathrm{~min}$ after initiation of the platelets aggregation in PRP by $7.5 \mu \mathrm{g} / \mathrm{ml}$ rat collagen. Control PRP $+7.5 \mu \mathrm{g} / \mathrm{ml}$ collagen $(-\mathrm{O}-)$, PRP $+7.5 \mu \mathrm{g} / \mathrm{ml}$ collagen $+1 \mathrm{U}$ AK after $1 \mathrm{~min}$. $(-\Delta-)$, PRP $+7.5 \mu \mathrm{g} / \mathrm{ml}$ collagen $+2 \mathrm{U}$ AK after $1 \mathrm{~min}$. (一口-).

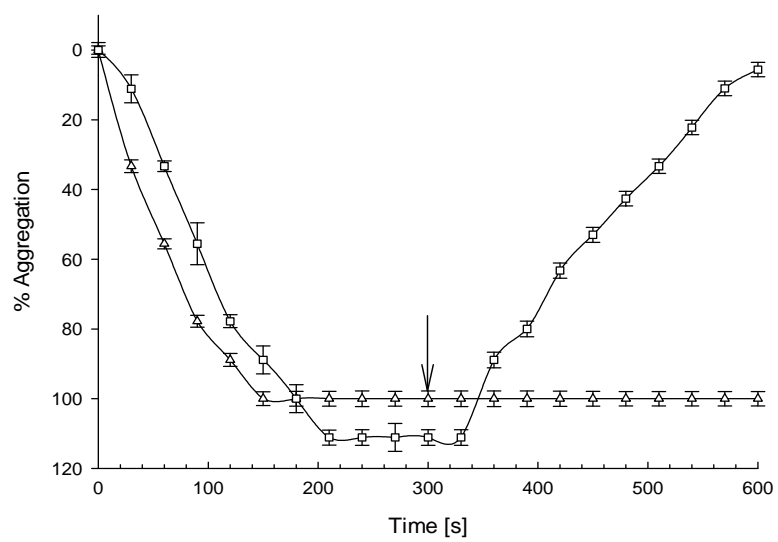

Figure 11. The influence of $2 \mathrm{U}$ adenylate kinase (AK) added 5 min after initiation of the platelets aggregation in PRP by $7.5 \mu \mathrm{g} / \mathrm{ml}$ rat collagen. Control PRP $+7.5 \mu \mathrm{g} / \mathrm{ml}$ collagen $(-0-)$, PRP $+7.5 \mu \mathrm{g} / \mathrm{ml}$ collagen $+2 \mathrm{U}$ AK after $5 \mathrm{~min}$. $(-\Delta-)$.

Table 3. Influence of AK on the concentration of purine nucleotides in PRP activated by $7.5 \mu \mathrm{g} / \mathrm{ml}$ rat collagen.

\begin{tabular}{|c|c|c|c|c|}
\hline \multirow{2}{*}{$\begin{array}{l}\text { Amount } \\
\text { of AK }\end{array}$} & \multirow{2}{*}{$\begin{array}{c}\text { Time of enzyme } \\
\text { addition }\end{array}$} & \multicolumn{3}{|c|}{ Nucleotides concentration $[\mu \mathrm{M}]$} \\
\hline & & AMP & ADP & ATP \\
\hline $\begin{array}{c}\text { No } \\
\text { enzyme }\end{array}$ & - & $66.7 \pm 6.3$ & $10.9 \pm 4.7$ & $26.3 \pm 11.3$ \\
\hline $1 \mathrm{U}$ & $\begin{array}{c}\text { Before activation } \\
\text { by rat collagen }\end{array}$ & $68.0 \pm 1.3$ & $12.9 \pm 0.3$ & $47.7 \pm 4.3$ \\
\hline $1 \mathrm{U}$ & $\begin{array}{c}1 \text { min after } \\
\text { activation } \\
\text { by rat collagen }\end{array}$ & $35.9 \pm 6.2$ & $36.0 \pm 1.1$ & $41.4 \pm 2.3$ \\
\hline $2 \mathrm{U}$ & $\begin{array}{c}1 \text { min after } \\
\text { activation by rat } \\
\text { collagen }\end{array}$ & $78.0 \pm 4.3$ & $14.4 \pm 0.3$ & $49.4 \pm 0.8$ \\
\hline $2 \mathrm{U}$ & $\begin{array}{c}5 \text { min after } \\
\text { activation by rat } \\
\text { collagen }\end{array}$ & $100.3 \pm 18.2$ & $8.8 \pm 8.9$ & $51.1 \pm 0.1$ \\
\hline
\end{tabular}




\section{DISCUSSION}

The nucleotide hydrolases and kinases are both engaged in the precise regulation of purines concentration in the vascular system therefore controlling the platelets aggregation process. Previous studies on platelets aggregation and thrombosis revealed that NTPDase1 (apyrase) inhibits activation of blood platelets [14,15]. The potato apyrase was used most often. However the latest experiments concerned human NTPDase1 produced by using a yeast expression system, purified, and reconstituted within lipid vesicles [25] or recombined human NTPDase1 expressed in bacteria [26].

The results of our studies indicated that in addition to antithrombotic effects of NTPDase1, also adenylate kinase is involved in regulation of aggregation. The increased activity of AK in patients after myocardial infarction is connected with appearance of another isoform of the enzyme. The occurence of another active isoform of AK can constitute an emergency mechanism maintaining the proper blood flow due to the clearance of circulating ADP. Likewise in Duchenne dystrophic patients, an additional isoform of AK was identified and separated on Blue-Sepharose column chromatography [27]. The increase of AK activity observed for patients after myocardial infarction confirmed its correlation with platelets aggregation.

The minimal efficient ADP concentration required for human platelet aggregation is $1.5 \mu \mathrm{M}$ [28]. We found that in pig blood the ADP and collagen concentrations required for the platelets aggregation in vitro are higher than in human blood. However, in the literature there is very little data concerning the pig platelets aggregation process. It cannot be excluded that there are differences between species in minimal ADP and collagen concentrations required to the platelets aggregation.

The decrease in ADP concentration may lead to terminating the platelets aggregation. Therefore NTPDase 1 (apyrase), which hydrolyses ATP and ADP to AMP, has an antithrombotic effect due to inhibition of aggregation but not to disaggregation of platelets [28]. Our experiments proved that aggregation process initiated by ADP as well as by rat collagen was blocked but not reversed in the presence of potato NTPDase1 (results not shown).

Unexpectedly, AK causes almost complete disaggregation of activated platelets up to five minutes after initiation of the aggregation process by collagen. These results are in agreement with the paper of Rysanek et al. [23], but their experiments concerned myokinase preparation containing ammonium sulphate. It is not clear that myokinase itself caused the disaggregation of platelets. In our experiments myokinase did not affected in neither inhibition of aggregation nor disaggregation of activated platelets (results not shown). The main difference between myokinase and adenylate kinase is their substrate specificity. The preferred substrate for myokinase is ATP while for adenylate kinase from B. stearothermophilus the $\mathrm{K}_{\mathrm{M}}$ for ATP is the same as for ADP. The value is $\mathrm{K}_{\mathrm{M}(\mathrm{ADP})}=0,037 \mathrm{mM}, \mathrm{K}_{\mathrm{M}(\mathrm{ATP})}=0,036 \mathrm{mM}$ respectively [29]. Therefore, during activation and aggregation of platelets, when high concentrations of ADP are present in the blood, adenylate kinase from B. stearothermophilus preferably uses two ADP molecules to synthesis of ATP and AMP. The decrease in ADP concentration simultaneous with the increase in ATP concentration may be the main requirement for disaggregation of platelets.

In the aggregation process induced by $20 \mu \mathrm{M}$ ADP, concentration of the nucleotide is high enough for the activated platelets to partially undergo irreversible aggregation $[30,31]$. In this case, NTPDase1 as well as adenylate kinase stop the aggregation, but do not trigger the disaggregation of platelets. ADP concentration in the samples activated by rat collagen is lower. The ATP: ADP ratio after the AK addition to the platelets activated by collagen is higher than that observed for platelets activated by ADP. The increase of ATP:ADP ratio is probably responsible for the initiation of disaggregation process. That explains why the aggregation may be reversed only in the case of platelets activation initiated by rat collagen.

In conclusion, the disaggregation process is possible in the appropriately low ADP concentration and only in the presence of adenylate kinase. However, the effects of adenylate kinase activity are diverse and multidirectional. The enzyme not only decreases the ADP level but also produces ATP and AMP. Dilation of blood vessels in the response to ATP decreases the blood pressure. AMP is hydrolysed by 5 '-nucleotidase to adenosine that inhibits blood platelets aggregation [32,33].

The platelet activation and aggregation occurs in the early stage of the thrombosis. The occlusive thrombus formation is a main cause of acute coronary syndromes and stroke in humans. Anticoagulative role of adenylate kinase indicates the possibility of using this enzyme as antithrombotic agent in the treatment of cardiovascular diseases, including myocardial infarction and ischemic stroke.

\section{REFERENCES}

[1] Jurk, K. and Kehrel, B.E. (2005) Platelets: Physiology and Biochemistry. Seminars in thrombosis and hemostasis, 31, 381-392.

[2] Willoughby, S., Holmes, A. and Loscalzo, J. (2002) Platelets and cardiovascular disease. European Journal of Cardiovascular Nursing, 1, 273-288.

[3] $\quad$ www.americanheart.org/presenter.jhtml?identifier $=4478$.

[4] Heptinstall, S., Johnson, A., Glenn, J.R. and White, A.E. (2005) Adenine nucleotide metabolism in human bloodimportant roles for leukocytes and erythrocytes. Journal of Thrombosis and Haemostasis, 3, 2331-2339. 
[5] Cattaneo, M. (2007) Platelet P2 receptors: old and new targets for antithrombotic drugs. Expert Review of Cardiovascular Therapy, 5, 45-55.

[6] Erlinge, D. and Burnstock, G. (2008) P2 receptors in cardiovascular regulation and disease. Purinergic Signal, 4, 1-20.

[7] Woulfe, D., Yang, J. and Brass, L. (2001) ADP and platelets: The end of the beginning. Journal of Clinical Investigation, 107, 1591-1598.

[8] Gachet, C. (2001) ADP receptors of platelets and their inhibition. Journal of Thrombosis and Haemostasis, 86, 222-232.

[9] Daniel, J.L., Dangelmaier, C., Jin, J., Ashby, B., Smith, J.B. and Kanapuli, S.P. (1998) Molecular Basis for ADPinduced platelet activation. Journal of Biological Chemistry, 273, 2024-2029.

[10] Kahner , B.N., Shankar, H., Murugappan, S., Prasad, G.L. and Kunapuli, S.P. (2006) Nucleotide receptor signaling in platelets. Journal of Thrombosis and Haemostasis, 4, 2317-2326.

[11] Yegutkin, G.G., Samburski, S.S. and Jalkanen S. (2003) Soluble purine-converting enzymes circulate in human blood and regulate extracellular ATP level via counteracting pyrophosphatase and phosphotransfer reactions. Journal of the Federation of American Societies for Experimental Biology, 17, 1328-1330.

[12] Yegutkin, G.G. (2008) Nucleotide and nucleoside -converting ectoenzymes: Important modulators of purinergic signalling cascade. Biochimica et Biophysica Acta, 1783, 673- 694.

[13] Quillen, E.E., Haslam, G.C., Samra, H.S., Amani-Taleshi, D., Knight, J.A., Wyatt, D.E., Bishop, S.C., Colvert, K.K, Richter, M.L. and Kitos, P.A. (2006) Ecto-adenylate kinase and plasma membrane ATP synthase activities of human vascular endothelial cells. Journal of Biological Chemistry, 281, 20728-20737.

[14] Marcus, A.J., Broekman, M.J., Drosopoulos, J.H., Olson, K.E., Islam, N., Pinsky, D.J. and Levi, R. (2005) Role of CD39 (NTPDase-1) in thromboregulation, cerebroprotection, and cardioprotection. Seminars in Thrombosis and Hemostasis, 31, 234-246.

[15] Atkinson, B., Dwyer, K., Enjyoji, K. and Robson, S.C. (2006) Ecto-nucleotidases of the CD39/NTPDase family modulate platelet activation and thrombus formation: Potential as therapeutic targets. Blood Cells Molecules and Diseases, 36, 217-222.

[16] Łęcka, J., Molski, S. and Komoszyński, M. (1999) Alteration of ectopurine metabolism in vascular disease. In Vanduffel L., Lemmens R. (ed.), Ecto-ATPases and related ectonucleotidases. Maastricht, Shaker Publishing $\mathrm{BV}$.

[17] Gellerich, F.N. (1992) The role of adenylate kinase in dynamic compartmentation of adenine nucleotides in the mitochondrial intermembrane space. FEBS Letters, 297, 55-58.

[18] Picher, M. and Boucher, R.C. (2003) Human airway ecto-adenylate kinase. A mechanism to propagate ATP signaling on airway surfaces. Journal of Biological Chemistry, 278, 11256 -11264.

[19] Noma, T. (2005) Dynamics of nucleotide metabolism as a supporter of life phenomena. Journal of Medical Investigation, 52, 127-136.

[20] Haslam, R.J. and Mills, D.C.B. (1967) The adenylate kinase of human plasma, erythrocytes and platelets in relation to the degradation of adenosine diphosphate in plasma. Biochemical Journal, 103, 773-784.

[21] Kędrowa, S. and Worsztynowicz-Jałowiec, E. (1971) Myokinase activity in myocardial infarction. Polish Medical Journal, 10, 805-811.

[22] Frithz, G., Ericsson, P. and Ronquist, G. (1976) Serum adenylate kinase activity in the early phase of acute myocardial infarction. Upsala Journal of Medical Sciences, 81, 155-158.

[23] Rysánek, K., Svehla, C., Spánková, H. and Mlejnková M. (1969) The effect of myokinase on the aggregation and disaggregation of thrombocytes. Experientia, 25, 31-32.

[24] Czarnecka, J., Cieślak, M. and Komoszyński, M. (2005) Application of solid phase extraction and high-performance liquid chromatography to qualitative and quantitative analysis of nucleotides and nucleosides in human cerebrospinal fluid. Journal of Chromatography B, 822, 85- 90

[25] Haller, C.A., Cui, W., Wen, J., Robson, S.C. and Chaikof, E.L. (2006) Reconstitution of CD39 in liposomes amplifies nucleoside triphosphate diphosphohydrolase activity and restores thromboregulatory properties. Journal of Vascular Surgery, 43, 816-823.

[26] Yang, M. and Kirley, T.L. (2008) Engineered human soluble calcium-activated nucleotidase inhibits coagulation in vitro and thrombosis in vivo. Thrombosis Research, 122, 541-548.

[27] Hamada, M., Sumida, M., Kurokawa Y., Sunayashiki -Kusuzaki, K., Okuda, H., Watanabe, T. and Kuby, S.A. (1984) Studies on the adenylate kinase isozymes from the serum and erythrocyte of normal and Duchenne dystrophic patients. Journal of Biological Chemistry, 260, 11595-11602.

[28] Łęcka, J. and Komoszyński, M. (2003) The role of ecto-adenosine and ecto-adenine nucleotides in regulation of blood pressure, haemostasis and etiology of atherosclerosis. Progress in Medical Research, 1, 48-74.

[29] Glaser, P., Presecan, E., Delepierre, M, Surewicz, W.K., Mantsch, H.H., Barzu, O. and Gilles, A.M. (1992) Zinc, a novel structural element found in the family of bacterial adenylate kinases. Biochemistry, 31, 3038-3043.

[30] Furie, B. and Furie, B.C. (2005) Thrombus formation in vivo. Journal of Clinical Investigation, 115, 3355-3362.

[31] Kuwahara, M., Sugimoto, M., Tsuji, S., Matsui, H., Mizuno, T., Miyata, S. and Yoshioka, A. (2002) Platelet shape changes and adhesion under high shear flow. Arteriosclerosis, Thrombosis, and Vascular Biology, 22, 329334.

[32] Wan, J., Ristenpart, W.D. and Stone, H.A. (2008) Dynamics of shear-induced ATP release from red blood cell. Proceedings of National Academy of Sciences, USA, 105, 16432-16437.

[33] Kawashima, Y., Nagasawa, T. and Ninomiya, H. (2000) Contribution of ecto-5'-nucleotidase to the inhibition of platelet aggregation by human endothelial cells. Blood, 96, 2157-2162. 